\section{Configuraciones más pequeñas, sueños más grandes}

No parece una casualidad quc en Italia, en este momento, las mayores energias y cupacidad de renovación se den unidas a experiencias administrativas locales. No sc trata de localismos, sino de crisis de las grandes categorías abstractas que necesitan urgentemente ser renovadas.

La ciudad es un mosaico. Su identidad ya no es monolítica, es compleja, hecha de mundos que se entrecruzan, a menudo sin llegar a encontrarse realmente. El imperativo más urgente es hallar formas de cohesión que no se superpongan a los mundos diferentes, sino al contrario, que los respeten y los valoren y al mismo tiempo los unifiquen. No se puede ocultar la dificultad de este trabajo, ni el conflicto que le es inmanente. La identidad está en el limite, en aquel estrecho margen que crea fricción entre los mundos, que los divide y los une. Sobre eso hay que trabajar. Sin suprimir el conflicto (seria una forma de anular también la relación), pero regu- lando el conflicto. Por otra parte, la democracia no es más, al fin y al cabo, que una forma pacifica de solucionar los conflictos. Para que sca así hay que respetar las reglas: para que tenga futuro no basta con buscar en el presente y en lo inmediato el criterio para solucionar los conflictos. Es preciso algo más: un ideal, un proyecto, un sentido que induzca a dejar aparte las diferencias más inmediatas. No podemos buscar en la nación lo que nos permita ver en perspectiva y ayude a superar las diferencias. La nación es una forma de unidad discutible. Necesitamos configuraciones más pequeñas y sueños más grandes. Europa, en su momento, hubicra podido jugar ese papel. No parece que hoy pueda hacerlo. Pero, si no reaccionamos, Occidente está perdido y con él se pierde aquella forma de capacidad crítica -insoportable hasta el cansancio y el cinismo- sobre la cual, sin embargo, se ha construido nuestra civilización. El ocaso corre el riesgo de no ser una lánguida despedida, como piensan hasta personas de reconocido prestigio. Sin embargo, lo que perderíamos no carcectía de importancia.

\title{
La sociedad civil en Polonia *
}

\author{
EUGENIUSZ GÓRSKI
}

Academica de Ciencias de Polonia

En general, casi ningún país de la Europa Central y Oriental goza de una tradición importante de sociedad civil democrática. Pero Polonia es un caso peculiar: aunque ausentes durante cierto tiempo, las tradiciones sociales de ciudadanía están relativamente arraigadas en la cultura política polaca '. Polonia disfruta, en efecto, de una rica tradición constitucional y de libertad, que se remonta a su célebre Constitución del 3 de mayo de 1791.

Empero, el temor de los polacos al absolutismo político y la total supremacía de la autoorganización social a expensas de

* Traducción de Max Slern. 
la organización del Estado fueron un obstáculo para la modernización del país y facilitaron el reparto de Polonia por sus vecinos a finales del siglo XVII. En el siglo XIX no existió Estado polaco alguno, aunque sí hubo numerosas formas de vida asociativa independiente, de sociedad civil opuesta a las dominaciones rusa, alemana y austríaca. Tras recobrar su independencia en 1918, Polonia se convirtió en un país incstable, aquejado de ultrapluralismo, de crisis económica y de fragmentación politica.

Acabada la Segunda Guerra Mundial, las tropas soviéticas erigieron en Polonia, como es sabido, un régimen comunista. En el centro y el Este de Europa, los regímenes comunistas perpetraron desde muy pronto todo jaez de ataques virulentos contra cualquier signo de sociedad civil. Durante la época estalinista se suprimió, en efecto, hasta el menor rastro de socicdad civil independiente y de vida societaria.

La idea de sociedad civil vino a la luz con el surgimiento de la oposición democrática a partir de 1976 . El principal teórico de la democracia post-totalitaria fue $\Lambda$ dam Michnik, cuyos escritos y actividades tanto contribuyeron al desarrollo de la sociedad civil democrática en Polonia y en los paises limitrofes. En El nuevo evolucionismo expuso Michnik un programa de lucha por las libertades civiles y los derechos humanos en Polonia, «dirigido a la opinión pública inclependiente más bien que a las autoridades. En lugar de decirle al Gobierno cómo habría de perfeccionarse, lo que tiene que hacer el programa cs decir a la sociedad lo que ésta ha de hacer. En la medida en que el Gobierno se interese por ello, no se le pucde dar mejor consejo que el proporcionado por la presión social que surja desde abajo» ${ }^{2}$.

So ha definido el surgimiento del sindicato «Solidaridad» como la recuperación de una esfera social, pública, y como la autoorganización de la sociedad civil con- tra el Estado comunista, en medio del proyecto de una «Polonia autogobernada». La sociedad civil surgida durante el periodo de «Solidaridad» en medio de una revolución pacífica y autolimitada fue la primera que apareció en un régimen de partido único de tipo soviético ${ }^{3}$.

En agosto de 1981, escribió Adam Michnik que la tarea principal del sindicato «Solidaridad» era la restauración de los vínculos sociales y dc una autoorganización encaminada a la defensa de los derechos humanos ${ }^{4}$. En una entrevista posterior, Michnik atribuyó a Vaclav Havel el haber sido uno de los primeros en emplear el término «sociedad civil» en la Europa comunista ${ }^{5}$. Sin embargo, Michnik y sus conmilitones de «Solidaridad" dieron a dicho concepto un nuevo significado, articulador de los sentimientos democráticos y antitotalitarios de la sociedad polaca, más bien que colectivista o comunitarista.

La promulgación de la ley marcial por el general Wojciech Jaruzelski se hallaba encaminada a destruir en Polonia la sociedad civil independiente. Aunque dicho propósito fracasase, el proceso de desarrollo de la sociedad civil no se intcrrumpió, sino que adquirió formas nuevas. El régimen militar no ha aniquilado nunca la esfera pública, que se mantuvo por mcdio de la prensa católica clandestina, extraoficial $\mathrm{e}$ incluso oficial, y gracias a numerosas publicaciones $e$ instituciones independientes ${ }^{6}$.

Ya en los últimos años ochenta surgieron nuevos conceptos de socicdad civil basados en un individualismo deudor del liberalismo económico, que suscitaron numerosas discusioncs; asî, por ejemplo, sobre el grado de democracia de los movimientos populares y sobre la necesidad de pluralismo y de organizaciones de vasto alcance ${ }^{7}$. También ciertos autores izquierdistas e incluso ideólogos del Partido Comunista comenzaron a predicar la idea de una socicdad civil socialista ${ }^{8}$. 
La historia real del tórmino «sociedad civil» en el lenguaje cotidiano de la prensa y de los medios de comunicación comenzó en 1989 durante la transición polaca a la democracia. El problema de cómo tomar más activos a los ciudadanos y de la resurrección de la sociedad civil fueron tratados por un numeroso grupo de discusión en la Mesa redonda entre las autoridades del Estado y la oposición de «Solidaridad».

El ritmo de la evolución política cobró mayor velocidad gracias al acuerdo suscrito en la Mesa redonda, a las primeras elecciones parlamentarias y a la victoria cspectacular de «Solidaridad» en dichas elecciones. El desorganizado y decrépito Partido Obrero Unificado Polaco (originariamente Partido Comunista) dejó pronto de ser la fucrza gohernante, perdió su posición de dirección y se convirtió en un elemento más, bien que pequeño, de la pluralista socicdad civil polaca. Después que sus micmbros disolvieran el partido semiconunista gobernante, su sucesor, el Partido Socialdemócrata de la República de Polonia, proclamó que sus fines eran la democracia parlamentaria y la socicdad civil que se gobierna a si propia.

En la Constitución enmendada de la República de Polonia, la palabra «socialista» fue sustituiua por la palabra «civil». Los llamados Comités Cívicos surgidos de «Solidaridad ${ }^{9}$, el Foro Cívico Parlamentario (OKP) y, en fin, la Unión Civil del Movimiento Democrático (ROAD) cobraron extraordinaria importancia. Pero la mengua de la participación política y los primeros sintomas de desafección por la libertad se apoderaron en seguida de la sociedad civil polaca, exhausta por las adversidades economicas.

Los primeros llamamientos en pro de la creación de un Estado civil y tambiën las primeras construcciones teoricas de un «socialismo civil» brotaron a finales de los años ochenta del interés por una sociedad civil concebida como una suerte de opo- siciỏn al Estado. El propio Tadeusz Mazowiecki, primero de los jefes de Gobieno no comunistas, declaró en su discurso del 26 de julio de 1990 que Polonia se hallaba empeñada en edificar un moderno Estado civil de derecho.

Conviene notar que, conforme fue aumentando la privatización de la cconomía polaca y ensanchándose la esfera de la libertad política bajo las condiciones del postcomunismo, términos por el estilo de "sociedad civil socialista» y «sociedad civil del socialismos cayeron en completo desuso en la prensa escrita. Hízose, por cl contrario, popular el término "sociedad civil» sin adjetivo ni complemento alguno.

El profesor Rafal Krawczyk, principal propagandista de la gran transformación socioeconómica del socialismo en una sociedad moderna capitalista (y civil), proclamó con su autoridad que la idea del "socialismo democrático" no era más que una ilusión y que la asociedad civil socialista " jamás seria realidad ${ }^{10}$.

De hecho, ya en los textos que escribian los ideólogos del extinto PUWP se hacía hincapié en la creación de un fundamento material para la sociedad civil en Polonia ${ }^{11}$. La sociedad civil desprovista de adjetivos pasaba a ser sinónimo de democracia participativa, «atributo de un Fstado de democracia parlamentarias 12 .

Al comienzo, el problema más agudo de las discusiones sobre la «sociedad civil»" era si ella podía existir o no dentro del "socialismo rcal». Hubo quienes sostenían que la falta de toda sociedad civil era constitutiva del socialismo real ${ }^{13}$, pero otros preferían hablar de una sociedad civil distorsionada, incompleta y aun socialista, según sucedió, como va dicho, en Polonia, y también en la Yugoslavia de entonces. Durante la profunda crisis de los países del socialismo real, la sociedad civil se identificaba la mayor parte de las veces tan sólo con la oposición anticomunista. 
Tras del colapso del socialismo en Polonia y cn otros lugares, vino a suscitarse una discusión nueva tocante a la naturaleza y funciones de la sociedad civil en los países postcomunistas. Radicaba el problema en el modo como podía aplicarse dicho término a la descripción de los nucvos procesos de transformación. El tracaso del socialismo corrobora la tesis de la supremacía de la sociedad civil sobre el Estado, pero nadic sabe cómo la primera, a la sazón truncada y pasiva, es capaz de formar y volver a producir una estructura plenamente desarrollada. Si hay que hacer caso de Ogrodzinski, semejante truncamicnto está preñado de peligros, ya que la sociedad civil, insuficientemente constituida, no es capaz de coordinar una vida social emancipada ${ }^{14}$.

En la Polonia de hoy día, ciertos publicistas toman a la sociedad civil por un ideal positivo, mientras que otros la miran con gesto de sospecha. Quienes le son adversos andan temerosos de que la idea de la sociedad civil amenace a la superior idea de nación. Los representantes de la tendencia derechista del nacionalismo crecida tras del derrumbe del viejo sistema hállanse, en efecto, algo turbados por el origen liberal izquierdista que tuvo la idea de marras en el contexto polaco.

Andrzej Sicinski, uno de los sociólogos polacos de mayor nombradía, ha abogado no hace mucho por darle al asunto de la sociedad civil la mayor importancia y ha expuesto un vasto programa de investigación multidisciplinar en torno al ideal de la sociedad civil y a los cambios presentes acontecidos en Polonia y en cl Este europeo. En el proyecto de su indagación se comprenden las mudanzas institucionales, la diferenciación social, los cambios de la vida cotidiana y los ocurridos en el sistema de valores de las sociedades civiles, los nuevos movimientos sociales $\mathrm{e}$ iniciativas económicas, la constitución de partidos politicos, el funcionamicnto del sistema repre- sentativo o el desarrollo y actividades de asociaciones profesionales y regionales de diverso tipo, entre otras cuestiones ${ }^{15}$.

Sostiene Sicinski que la sociedad civil concebida como una aspiración es necesaria para la existencia de las élites que representan hoy la diferenciación de intereses c ideas. Ha advertido este autor un círculo vicioso en la Polonia de la hora presente: la falta de sociedad civil impide la creación de minorias representativas, y la falta de este tipo de minorías atrofia la creación de sociedad civil» "'. Otros obstáculos para la constitución de una socicdad civil efectiva en Polonia son el estado depauperado de la economía nacional, la debilidad de las clases medias, el bajo grado de institucionalización de los partidos políticos, la ausencia de vínculos sociales y de otros mecanismos caracteristicos de la sociedad civil de tipo occidental. Sicinski ha advertido sin embargo un aumento considerable de organizaciones y asociaciones populares, acciones caritativas y cosas análogas, todo lo cual constituiría según él una versión nueva de la socicdad civil, digna de no poco interés.

En su comunicación presentada a un congreso extraordinario celebrado por el Instituto Civil de Varsovia, olro miembro de la comunidad académica, la profesora Hanna Swida-Ziembra, ha visto más obstáculos, y muy numerosos, para constituir en Polonia una sociedad civil. Tales obstáculos se hallan, según esta autora, acrecidos por la actitud egoísta de la mayor parte de los políticos, que han perdido todo su prestigio en una Polonia desencantada y abandonada a la desorientación ${ }^{17}$.

Según el profesor Bronislaw Geremck, uno de los caudillos históricos de «Solidaridad", el concepto de sociedad civil ha de conservar su validez en las sociedades postcomunistas. No cree él que las esperanzas del sindicato en la creación de una sociedad civil fuesen una simple ilusión, aunque admite que la sociedad no se ha 
convertido cn un terreno firme sobre el que pudicra cdificarse la democracia fácilmente. Al dar cuenta de la magia inicial de la palabra "ciudadano» en el extinto socialismo y de la posterior decepción postcomunista, ha advertido Geremek que «la socicdad civil de 1980 fuc la proyección hacia cl futuro de una visión que sc fundaba en una pasmosa unidad emocional. La sociedad civil de diez o más años después no puede fundarse en emociones ni tampoco debe hacerlo, sino más bien en la cuidadosa construcción de instituciones, en la realización práctica de valores éticos y en la participación en la vida pública del mayor número posible de gentes. La tarea principal ahora es edificar mecanismos democráticos de estabilidad, tales como frenos y cquilibrios constitucionales, educación civica animada por un espiritu de respeto al derccho, y estímulo en pro del activismo ciudadano. La sociedad civil, concluye este autor, no actúa en oposición al Estado democrático, sino que coopera con él. Ha de dcjar de concebirse como una «polis paralela» para no ser otra cosa que suna parte de la polis" is.

Importa destacar que la Iglesia católica polaca desempeñó un papel notable en la constitución de un contrasistema ${ }^{19} \mathrm{y}$ una sociedad civil bajo el comunismo, aunque el advenimiento de la democracia tornó ambiguo dicho papel. La fucrza tradicional de la Iglesia puede resultar peligrosa para una sociedad civil plenamente autónoma, y aun provocar nuevos conflictos en lo futuro. Al pasar de la dictadura a la democracia, habrá de encontrar la Iglesia su lugar on una sociedad civil pluralista, o incluso llegar a tener que esforzarse por la hegemonía en lugares como Polonia, donde siempre anduvo estrechamente ligada a las aspiraciones nacionales ${ }^{20}$.

la nueva situación en Polonia exige también acabar no sólo con los mitos fundamentalistas de la justicia social y de la unidad de los primeros tiempos de «So- lidaridad", sino también acabar con el concepto paternalista del Estado. Según Jadwiga Staniszkis, brillante y destacado estudioso de los tránsitos habidos en el Este de Europa, la creación de una genuina sociedad civil es un fenómeno muy complejo, un proceso no exento de dolor que exige tanto la privatización de la cconomía como mudanzas culturales profundas ${ }^{2}$.

Todos los esfuerzos por crear una socicdad civil significativa en Polonia fracasa. ron, y un postrer intento de resucitarlos lo llevó a cabo el presidente Lech Walesa en su proclama a la nación del 13 de julio de 1993 en favor del llamado Bloque No Partidista en Pro de las Reformas. Los partidos políticos, débiles y minoritarios, no le prestaron eco.

Lo pcculiar de la situación polaca radica en que cl Estado, por paradójico que pueda esto parecer, es una herramienta indispensable para la construcción de la sociedad civil ${ }^{22}$. La mano invisible del mercado libre ha resultado insuficiente para reavivar a la sociedad polaca, pasiva y desorientada, y a las de otros paises del Este de Europa.

Hay una necesidad creciente de conservar y cuidar de todas las reglas del derecho en una sociedad nueva, llena de egoísmo, de abuso económico y de patologías sociales. Un crecido número de autores creen que la lcy y la nueva Constitución tomadas como un supremo acto normativo (algo inédito en Polonia) es condición previa para el desarrollo de la sociedad civil. A toda sociedad civil la estabiliza y le da su dinámica propia el derccho ${ }^{23}$.

Además, la idea simbólica de socicdad civil en Polonia debe más inspiración al nacionalismo tradicional y a los sentimientos comunitarios particulares que a los valores genuinamente liberales ${ }^{24}$. Se ha dicho también que la amarga herencia del comunismo ha legado un tipo especitico dc mentalidad humana: el llamado homo sovieticas, un ser humano pasivo, despro- 
visto de iniciativa y de imaginación ${ }^{25}$. Las secuelas de lo anterior no pueden, en verdad, favorccer mucho el progreso en el tejido económico de la sociedad civil.

Después de 1990 la sociedad polaca parecía perdida. Se diría que mostraba indicios de indefensión aprendida, que tendía a retirarse de la vida pública sociopolítica durante la recesión cconómica. Como resultado de ello, la sociedad comenzaba a experimentar formas nuevas de anomia social ${ }^{26}$

De hecho, la socicdad civil en Polonia es todavía una ideología utópica particular, más bien que una realidad concreta. Pero la idea de sociedad civil ha perdido su fuerza inicial y le está llegando la hora de su crisis ${ }^{27}$.

\section{NOTAS}

1 Wd. Andrzej W. Jablonkki, «The Dilemmas of Denocratization in the Post-Communist Central Europe. A Political-Cultural Approach», en A. W. Jablonski, W. Piasecki (eds.), Totalitarianism and the Challenge of Democracy (Wroclaw, 1992), pp, 59-60, y Barbara Markicwicz, aLiberum veto, dlbo o granicach spoleczenstwa obywatelskiego" ("Liberum veto o los limites de la sociedad civilm), en Obywatel. Odrodzenie pojecia (El cildadana La resurreción del concepto) (Varsovia. 1993), pp. 74.84.

Adam Michnick, The Now Ebolutionism. Survey 1976. 344, p. 263. Vk tambien J. Rupnik sissent in Poland, 1968-78: The End of Revisionism and the Rebirth of Civil Societym, en L. Tokes (ed.), Opposition in Eastern Europe (Londres: Macmillan, 1979), ycffrey C. Goldtarb, Reyond Glasnost. The Post-Totalitarian Mind (Chicago/Londres: The University of Chicago Pres, 1989), pp. 142-157.

3id. Janina Frentzel-Zagôska, *Civil Socicty in Poland and Hungarys, Soviet Studies (1990), 4.

- Adam Michnik, "The Promise of a Civil Socictym, en su libro letters from Prison and other Essays (Berkeley/Los Ángeles: University of Califonnia Press, $1985), \mathrm{p}, 124$

5 «Towards a Civil Socicty: Hopes for Polish Democracy», The Times Literay Supplemen (1988), 4.

- Vhd. Hanna M. Fedorowicz, "Civil Society in Poland: Laboratory for Democratization in Central Europe», Phiral Societies (1990), vol. XXI; Leszek Nowak, Power and Civil Sacien. Toward a Dynamic Theory of Reat Socialism (Nueva York, 1491); María Markus, "Constitution and Functioning of a Civil Socicty in Poland", on Bronislaw Misztal (ed), Poland after Solidarity: Soctal Movements verstus the State (Nuevia Brunswick, 1985).

? Jcan L. Cohon y Andrew Arato, Chil Sockty and Political Theory (Cambridge, Mass. 1991). pp. $31-36$.

"Por cjemplo Jerzy Wiatr, Marksizm i polityka (Marxismo y poltica) (Varsovia, 1987), y Artur Bodnar, Spoleczenstwo obywatelskie-probleny interpretacyine ( $\mathrm{La}$ sociedad civit problemes de imerpretución) (Varsovia. 1989).
${ }^{9}$ Vid. Andrzej Bukowski, Komitety obywatelskit-ruch cpoki premiarm ( (eomités Ciudadanos-Movimiento de la Epoca de los Cambioso , Sindia Polityczne $(1993), 1 / 4(5)$.

ta Rafal Krawcryk, Wielka przemiana. Lpadek i odrodzenie polskiej gospodarki (El gran rambio. Caida y renacimienso de la ecomomia polaca) (Varsovia, 19\%0), p. 19. También Tomaz Mastnak ha becho ver que la sociedad civil se concibio inicialmente como alternativa más que como oposición y gue en un primer momento fue concebtda como "sociedad civil socialista", si bien «pronto se vio que se trataba de una contradicción en los terminos". Cfi. " $\mathrm{l}$. Mastnak, "Civil Society in Slovenia: From Oppusition to Powers, en P. Lewis (cd), Democracy and Cinil Socien in Eastem Europe. Selected Papers from the fourth World Congress for Soviet and East European Sizdies (Nueva York, 1992), p. 134 .

1 Artur Bodnar, «poleczenstwo abywatelskie... $\eta_{t}$ cit., p. 3 .

13 Wadyslaw Markiewicz, «Spoleczenstwo obywatelskje a demokracja” («Sociedad civil y democracia"), Nowe Drogi (1989), 7, p. 9.

1.3 Jadwiga Staniszkis, The Ontology of Socialism (Oxford: Clarendon Press, 1992).

${ }_{14}$ Piotr Ogrodzinski, Piec tekstów os spoleczenswiz obywatelskim (Cinco textos sobre la sociedad civil), Varsovia.

1 Andrzej Sicinski, tSpoleczenstwo obywitelskie jako przedmiot badan spolecznych w Polsees (a La suciedad civil como objeto de investigación social en Polonias), en 0 . Sochacki (ed.), Socjologia polityki $w$ Polsce (Gdanks), pp. $39-48$.

16 Andrzej Sicinski, "Elites" and "Masses" in Post-Comnunist Countries. The Polish Casen, en Atdona Jawlowska, Marian Kempny (eds.), Cultarat Dilemmas of Post-Communist Societies (Varsovia, 1994), p. 206.

1 Hanna Swida-Ziembra, «Spoleczenstwo Obywatelskie, politycy, zycie codzienne» (uLa socicdad civil, los politicos y la vida colidianas), Wez (1992), 8; vid tambiên Wiktor Osiatynoki, "Szalenstwo polity- 
kow (aLa pura locura de los políticosm), Gazetn Wyborcza, 18 de julio de 1992.

" Bronislaw Gercmek, aCivil Society Then and Nown, Joumal of Democracy (1992), vol. 3, 2. Vhase tambićn su articulo "Die Civil Society gegen den Kommunismus: Polens Botschafts, en K. Michalski (Hrsg.), Eiropa und die Civi Society (Stuttgart, 1991).

* R. Sharlet, wuman Rights and Civil Society". en W. Griffith (ed), Eastem Europ: The Opening Curtain? (San Francisco/Londres: Westview. 1989).

* Jose Casanova, «Kosciol wobec wyboru" ( La Iglesia frente a una elecionn), Res Publica (1991), 9:10.

3 Jadwiga Staniszkis, The Dynamics of the Breakthrough in Eastm Europe: The Polish Experience (Berkeley-Los Angeles-Oxford, 1991), p. 26.

" Maciej Potepa, "Rewolucja, spoleczenstwo obywatelskic, demokracja» ("Revolución, sociedad civil y democracia»), en Tadeusz Buksinski (cd.), Filozofia w dobie przemian (La flosofia en un periodo de tronsformaciones) (Poznan, 1994), p. 262.

"Vid. Krzysztof Wrzesinski, "Panstwo i prawo a spolezenstwo obywatelskie* ( El Estado, el derecho y la sociedad civils), Studia filozoficzne (1090), 4, y tambièn Janina Zakrzewska, «Prawu w spoleczenstwie obywatelskim» ("El derecho en la sociedaxl civil»), en Obywatel Odrodzerit, cit. pp. 107-112.

if Vit. Maciej Potepa, op. cil, p. 263, y Tadeusz Buksinski, Apoleczenstwo obywatelskie spoleczenstwo tynkowe" ( $\mathrm{L}$ a sociedad civil y la sociedad de mercados), en Filosofa w doble premian. cit., p. 284.

to Jozet Tischner, Eyka Solidamosci oraz Homo Sovieticus (Cracovia, 1992); Aleksander Smolar, "Vom Homo Sovicticus zum Burgurs, Trantit (1993), 3.

* Lena Kolarkka-Bobinska. Aspirations, Vakes and Interests. Poland 1989-9f (Varsovia: IFIS Publishers, 1994).

27 Más información de interés sobre la idea de sociedad civil en Polonia y en la Europa del Exte se encontrará en Jerzy Szacki, *Eín neues I and? Traum und Wirklichkeit der polnischen Demokraticn, Transit (1990), 3; Jcrzy Szacki, Liberalizm po komunizmie (El liberatisno después del comunismo) (Cracovia, 1994), pp. 90-145; Zbigniew Pescrynsk, "Solidarity and the Rebirth of Civil Sociely in Poland», en John Keanc (cd.), Civit Socery and the State. New European Perspectives (Londres, 1988); Zhignicw Rau (ed.), The Ree mergence of Citil Society in Eastern Europe and the Sovier Union (Boulder: Westview Press, 1991).

\title{
Participación, ciudadanía y democracia: ¿hacia el tercer sistema?
}

\author{
ROBERTO R. GUERRA \\ Universidad de La Laguna
}

La hegemonia de una concepción de la política, tan cínica como instrumental y elitista, unida a las insuficiencias y promesas incumplidas de las democracias reales, ha empezado a generar en las sociedades occidentales desarrolladas cierto pesimismo sobre el futuro de la forma de gobierno democrático. No debe sorprendernos por tanto que junto a los acríticos festejos por el triunfo de la democracia liberal asistamos desce hace algunos años a la percepción de su paradójica crisis. Buena parte de la teoría política actual tiende así a mostrarse profundamente preocupada no sólo por la tendencia de amplios sectores ciu- dadanos a asociar la política y la democracia con comportamientos y actitudes ligadas a la corrupción, la mentira y el clientelismo, sino también por fenómenos como el reducido margen de participación que permiten los sistemas democráticos imperantes, o la progresiva pérdida de afiliación de los partidos políticos y su cyidente agotamiento como instrumentos de mediación entre el ciudadano y el estado. En un panorama tan preocupante, en el que la política y la democracia parecen haberse divorciado definitivamente de la participación y acción política ciudadana, la publicación de una obra como la de 